\title{
Vaginal Adenosis in a 40-year-old Lady: A Case Report and Review of Literature
}

\author{
Shamsun Nahar Begum Hena, Nasrin Akhter, Sakti Das, Afroza Kutubi
}

\begin{abstract}
Vaginal adenosis, without a history of diethylstilbestrol (DES) exposure, is a rare condition with an unclear etiology. A 40year-old female presented with complaints of persistent excessive watery vaginal discharge. On examination, there was red, patchy, diffuse lesion all over the vaginal wall and cervix. Histopathological examination of the lesion revealed vaginal adenosis. This case is presented here for its rarity.
\end{abstract}

Keywords: Vaginal adenosis, Adenomatosis vaginae, Treatment.

How to cite this article: Hena SNB, Akhter N, Das S, Kutubi A. Vaginal Adenosis in a 40-year-old Lady: A Case Report and Review of Literature. J South Asian Feder Obst Gynae 2013;5(2):80-82.

\section{Source of support $\mathrm{Ni}$}

Conflict of interest: None declared

\section{INTRODUCTION}

Vaginal adenosis is used for a specific abnormality of the vagina. Here, the normal squamous epithelium of vagina is replaced by the columner gland bearing epithelium causing active secretion of profuse clear mucous. Bonney and G lendining first describe a case in 1910 in their article, 'A denomatosis vagina, a hitherto undescribed condition'. ${ }^{1}$

This rare pathology defined as the presence of müllerian type epithelium within the vaginal wall, which is presumed to be derived from persistent müllerian epithelium islets in postembryonic life. ${ }^{2,3} \mathrm{Here}$, there is differentiation of original indifferent müllerian cell or metaplasia of müllerian cell. Spontaneous vaginal adenosis appears to be fairly common in adult women, but it is mostly an insignificant finding on physical examination. ${ }^{4}$

Little is known about the etiology, pathogenesis, symptomatology and management of this poorly understood condition. But its association with in utero exposure to diethylstilbestrol (DES) and a subsequent high risk of clearcell vaginal adenocarcinoma is well known.,

Since the withdrawal of DES from the market, this condition is rarely described in the medical literature.

A sit is a rare condition, so the diagnosis may be overlooked. However, it should be considered as a possible differential diagnosis in women with persistent vaginal discharge.

A 40 years multipara with vaginal adenosis is reported here along with discussion of treatment options.

\section{CASE REPORT}

A 40-year-old lady, para 7, A LC 3 years, was presented with excessive vaginal discharge for 12 years and got admitted in
Obstetrics and Gynecology Department of Sir Salimullah M edical College and M itford H ospital, as a case of VVF. She was regularly menstruating lady with occasional menorrhagia. She developed profuse nonirritant vaginal discharge 1 month after delivery of her third baby 12 years back. Initially discharge was less in amount but gradually it was increasing day by day. It was neither associated with foul or uriniferous smell nor with itching. She had no urinary problem and normal urge for micturition. She al ways need protective underclothing for her discharge. There was no dermatological abnormality. Large amount of clear thin mucous were poured out through introitus which she complained as incontinence of urine.

Continuous discharge causes wash leather appearance of vulval skin (Fig. 1). On speculum examination, the mucosa of the whole vagina was hyperemic, stippled granul ar appearance with sharply demarcated margin (Fig. 2). No urinary incontinence was demonstrated by direct dye test and three swab test. A bout $250 \mathrm{ml}$ secretion occurred per day (Fig. 3). L evel of creatinin in vaginal secretion was $0.7 \mathrm{mg} / \mathrm{dl}$ (normal blood level).

Pap smear showed moderate inflammation. HV S and endocervical swab for Gram staining and $C / S$ revealed no abnormality. TVS report revealed bulky uterus and engorged vessel in upper part of vagina. Cystoscopy was normal. EUA revealed reddish, granular lesion in whole vaginal wall except few small areas and narrow collar round the cervix. Uterus was bulky, and cervix normal. Histopathology of tissue from vaginal wall revealed glandular element lined by mucin producing endocervical type of epithelial cells (vaginal adenosis) with mild inflammation (Figs 4 and 5). Endometrial tissues are in proliferative phase. $V$ aginal lesions were cauterized under regional anesthesia in phases without significant improvement. So, she need vaginal hysterectomy al ong with resection of adenomatous vaginal wall.

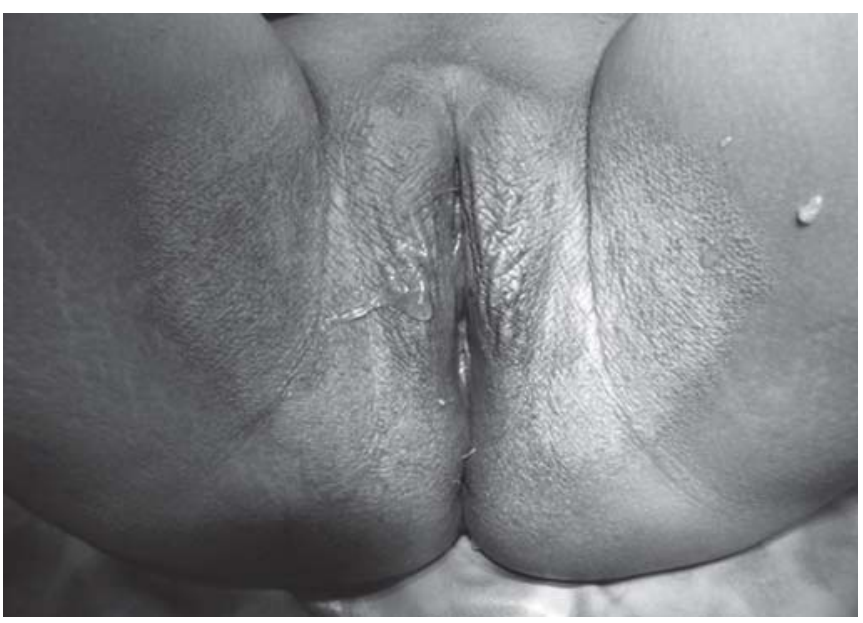

Fig. 1: Macerated appearance of vulva 


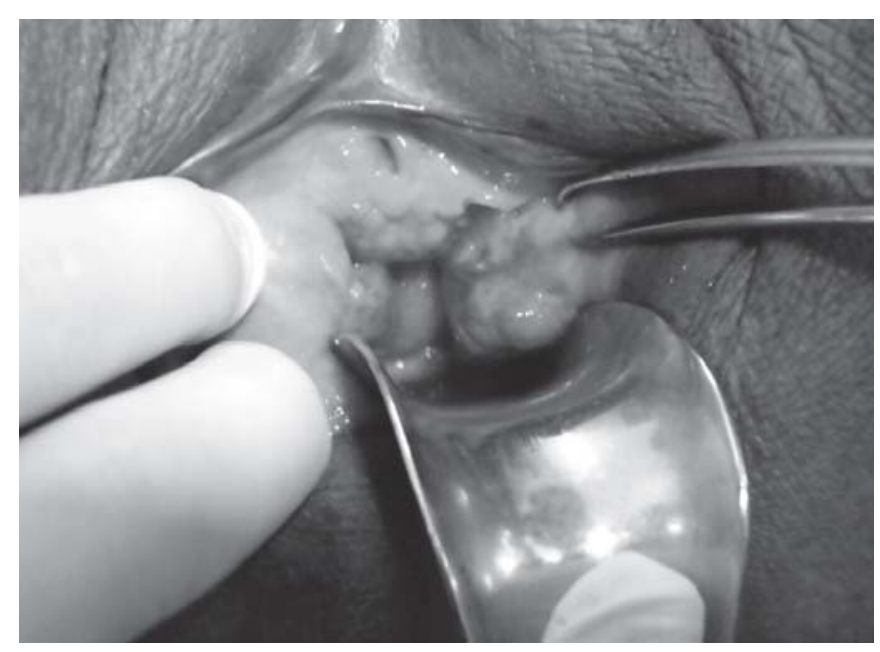

Fig. 2: Vaginal adenosis visible on posterior and lateral wall of vagina

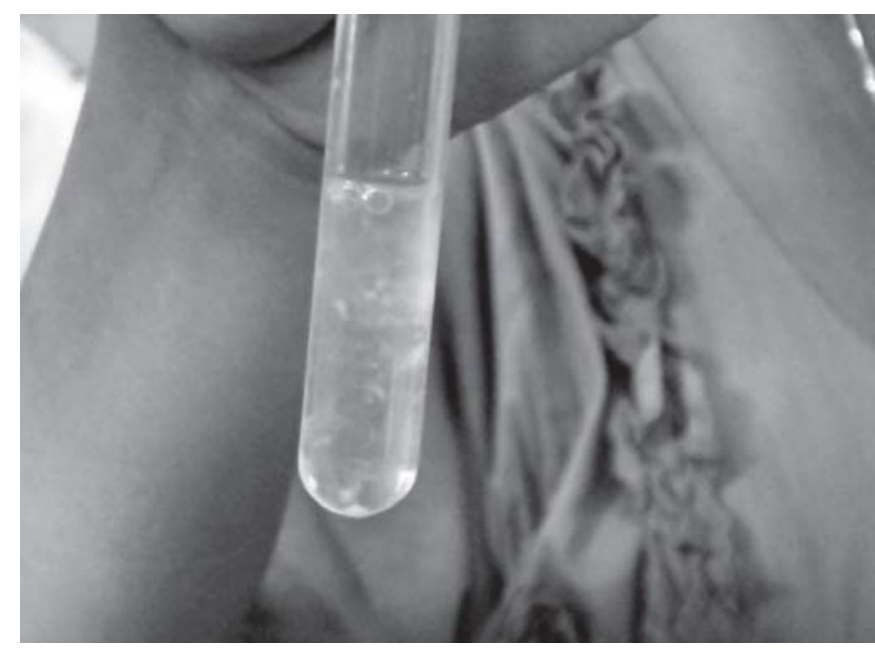

Fig. 3: Discharge of vaginal adenosis

\section{DISCUSSION}

The vagina is lined by noncornified squamous epithelium. A $n$ occasional mucous secreting gland may be found in the vaginal mucosa of normal women. It may be small multiple, discrete and without clinical symptom. ${ }^{2,6,8}$ Sandberg (1968) in his study on autopsy of vagina found occult vaginal adenosis in $41 \%$ of postpubertal girl in comparison to prepubertal girl.

The clinical appearance of vaginal adenosis is varied. It may present as patchy or diffuse red stippling, granularity or nodularity, single or multiple cysts, erosions, ulcers or even warty protuberances. Occasionally, the process may extend into the vulva. ${ }^{5}$

The symptoms mostly reported as profuse mucoid vaginal discharge, soreness of the vaginal introitus, vaginal bleeding independent of the menstrual cycle (often precipitated by sexual intercourse).

The etiology and effective treatment is unknown. Trauma and inflammation have been reported as pathogenic factors. Though, it is unclear but some studies shows that oral contraceptives play a role in the etiology. Symptomatic vaginal

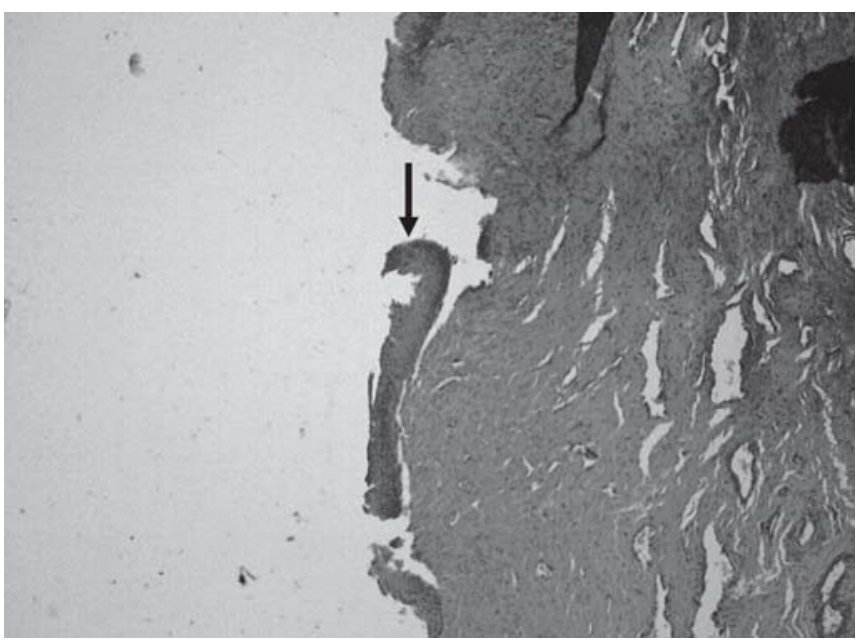

Fig. 4: Photomicrograph of vaginal adenosis

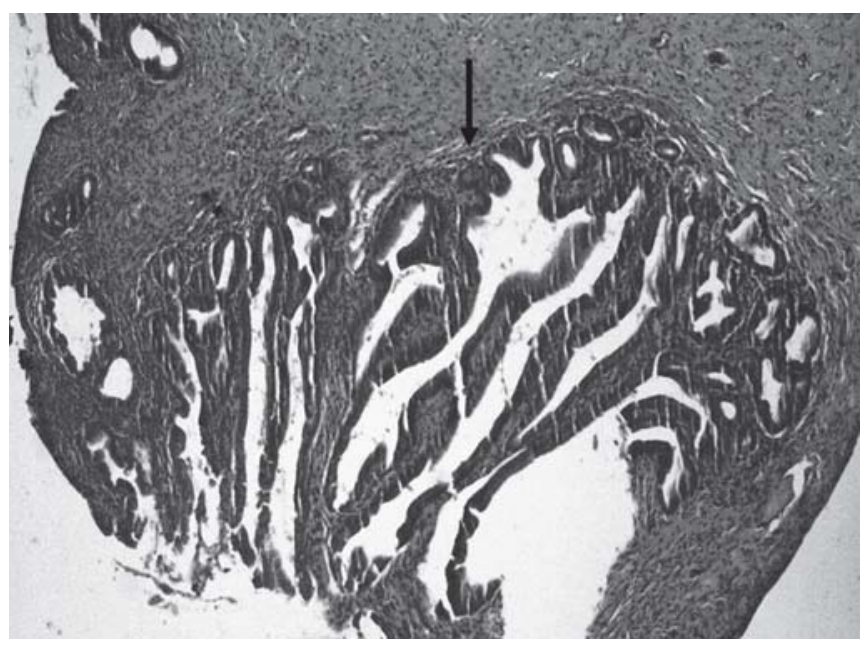

Fig. 5: Photomicrograph of vaginal adenosis showing glandular tissue

adenosis in postpartum period may be due to trauma or atrophy of the vaginal wall. ${ }^{7}$ Dysplasia of epithelium in vaginal adenosis may occur and turn into adenocarcinoma.

According to current opinion, spontaneous squamous differentiation is thought to occur in most women, if left untreated. The option to wait for spontaneous resolution may not be feasible, if subjective symptoms are severe impairing the quality of life, as in the present case.

Treatment of vaginal adenosis is also a difficult one. The aim of the treatment is to destroy the superficial columnar epithelium and replace by mature squamous epithelium. ${ }^{7}$

$\mathrm{CO}_{2}$ laser coagulation can be performed for this purpose. ${ }^{5}$ In resistant cases, vaginal resection with graft may be considered as an ultimate therapeutic option.

In our case, cauterization with a unipolar cautery was chosen to eliminate the lesions. This therapeutic intervention is a simple and available one. Cauterization was done in phases but without any improvement. So after 2 months, vaginal hysterectomy along with resection of adenomatus vaginal wall was performed. Postoperatively her condition improved satisfactorily. 


\section{CONCLUSION}

Although vaginal adenosis is a rare and generally asymptomatic, it should be part of the differential diagnosis in young patients with persistent vaginal discharge resistant to treatment. Although the etiology of the disease is unclear, it has been suggested that inflammation may have an effect on the pathogenesis of vaginal adenosis without a history of DES exposure. Any suspicious area should have cytological examination and excised or destroyed by diathermy.

The possibility of adenocarcinoma of the vagina developing from this lesion should al ways be considered, so careful followup is essential. ${ }^{1,5}$

\section{REFERENCES}

1. Bonney V, Glendining B. A denomatosis vagina: A hitherto undescribed condition. Proc R oy Soc M ed 1910;4:18-25.

2. Accetta SG, Rivoire W A, M onego HI, et al. V aginal adenosis in a non-diethylstilbestrol exposed 6-year-old patient. Gynecol Obstet Invest 2001;51(4):271-73.

3. M eehan FP, Spriggs AS, Strong SJ, W illiams EA . A denosis vagina. Case report. J Obstet Gynaecol Br Commonw 1996;76:165-67.

4. Chattopadhyay L, Cruickshan DJ, Packer M. Non diethylstilbestrol induced vaginal adenosis: A case series and review of literature. Eur J Gynaecol Oncol 2001;22(4):260-62.

5. Siders DB, Parott MH, A bell MR. Gland cell prosplasia (adenosis) of the vagina. A m J Obstet Gynecol 1965;91, 190-203.
6. Robboy S. Vaginal adenosis in women born prior to the diethylstilbestrol era. Hum Pathlol 1986;17:488-92.

7. Singer A, M ansell ME, N eill S. Symptomatic vaginal adenosis. British J Obstet Gynaecol 1994;101:633-35.

8. Stabler F. The treatment of adenosis vaginae. J Obstet Gynec Brit Cwith 1967;74:493-98.

\section{ABOUT THE AUTHORS}

\section{Shamsun Nahar Begum Hena (Corresponding Author)}

Professor and Head, Department of Obstetrics and Gynecology, Sir Salimullah M edical College and M itford H ospital, Dhaka, Bangladesh Phone: +8801712037415, e-mail: snhena@yahoo.com

\section{Nasrin Akhter}

A ssistant Professor, Department of Obstetrics and Gynecology, Sir Sal imullah M edical College and M itford H ospital, D haka, Bangladesh

\section{Sakti Das}

A ssistant Professor, Department of Obstetrics and Gynecology, Sir Salimullah M edical College and M itford H ospital, Dhaka, Bangladesh

\section{Afroza Kutubi}

A ssistant Professor, Department of Obstetrics and Gynecology, Sir Sal imullah M edical College and M itford H ospital, Dhaka, B angladesh 